\title{
Distal Migration of an Esophageal Prosthesis: a New Technique for Endoscopic Retrieval
}

Placement of an endoscopic prosthesis is an established technique for palliation of neoplastic esophageal stenoses. Unfortunately, the prostheses may migrate downward in the stomach, retrieving them may be difficult, and the methods used (i.e., rat-toothed forceps, balloons, polypectomy snares, a Nottingham introducer, or the hooked distal tip of the scope) often fail $(1,2)$. We propose the following new technique for stent retrieval.

We grasp the stent at its proximal tip with a polypectomy snare, cut away the snare handle (Figure 1), withdraw the scope, leaving the snare insitu and held with a knot. We introduce the scope again, and pass it through the stent (Figure 2). Finally, we remove the stent, by pulling at the snare, using the scope as a rail. The safety and effectiveness of this new technique is confirmed by our experience of six successful applications (two after failure of other methods and four treated using our method as the first choice).

\section{References}

1 Celestin LR, Etienne J, Raimbert P, et al.: Traitement endoscopique des stenoses oesophagiennes par prosthèse de Celestin. Nouv. Presse Méd. 1980; 9: 2155-2160.

2 Tytgat GNJ, Jager DFCA: Endoscopic prosthesis for advanced esophageal cancer. Endoscopy 1986; 18 (Suppl. 3): 32-39.

\section{Tampieri, O. Triossi, G. Melandri, G. Michieletti, T. Casetti} Gastroenterology and Endoscopy Unit

S. M. delle Croci General Hospital

Via Irpinia 16

48100 Ravenna

Italy

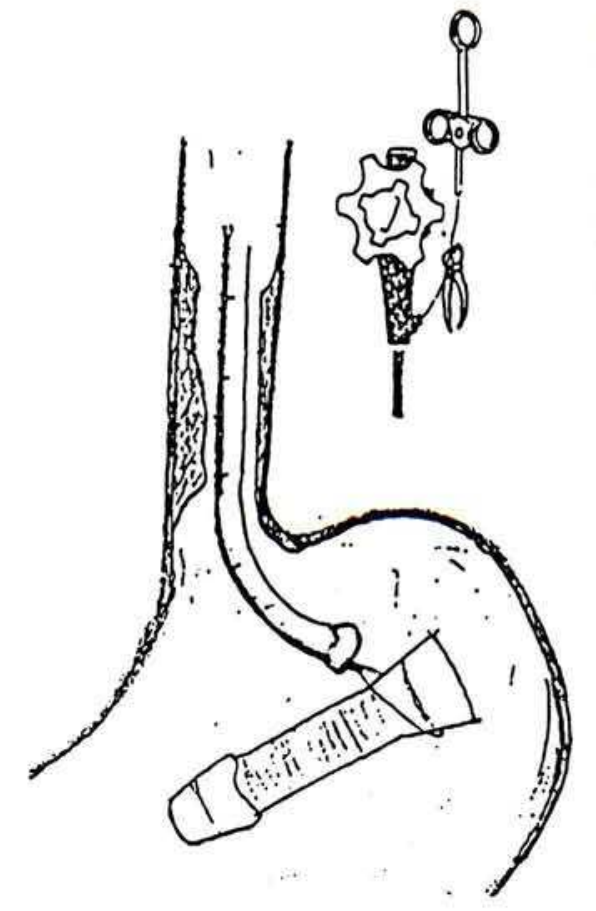

Figure 1:

The prosthesis grasped with a polypectomy snare, and the snare handle while a nurse is cutting it.

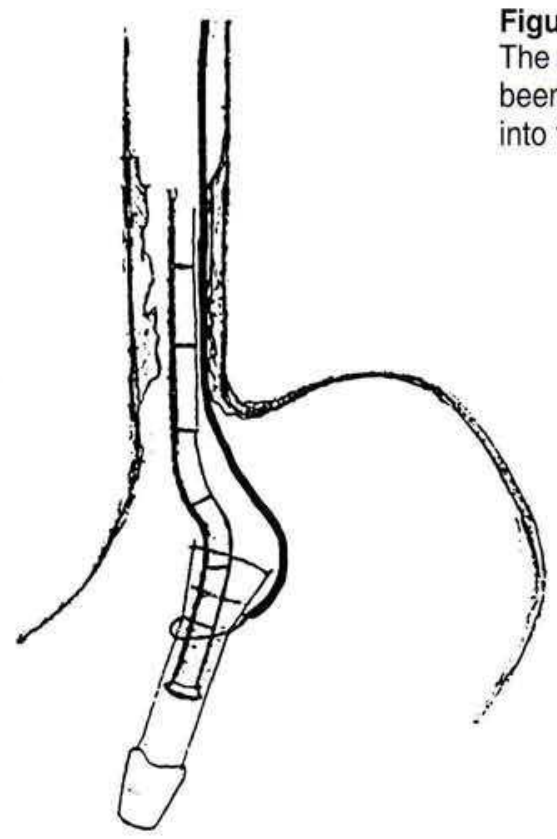

